\section{Skapula Örneklerinin Morfometrik Değerlendirilmesi ve Anatomik Varyasyonları}

* Sorumlu Yazar / Corresponding Author: Ahmet Nadir Aydemir Pamukkale Üniversitesi Tıp Fakültesi Ortopedi ve Travmatoloji Anabilim Dalı 20070 Kınıklı, Denizli / TÜRKIYE E-posta: anaydemir@yahoo.co.uk

\author{
Ahmet Nadir Aydemir ${ }^{1 *} \odot$, Mehmet Yücens ${ }^{1} \odot$, Şule Onur ${ }^{2} \odot$ \\ 'Dr. Öğr. Üyesi | Pamukkale Üniversitesi, Tıp Fakültesi, Ortopedi ve Travmatoloji Anabilim Dalı, \\ Denizli/TÜRKIYE \\ ${ }^{2}$ Dr. Öğr. Üyesi | Pamukkale Üniversitesi, Tıp Fakültesi, Anatomi Anabilim Dalı, Denizli/TÜRKiYE \\ Alındı/Received: 27 Mart / March 2020 \\ Düzeltildi/Revised: 14 Mayıs / May 2020 \\ Kabul/Accepted: 15 Mayıs / May 2020 \\ Yayımlandı/Published: 29 Haziran / June 2020
}

$\ddot{O} z$

İskelet sisteminin en büyük yassı kemiklerinden olan skapula göğüs duvarının arkasında yer almaktadır. Skapulanın kendine has morfometrik özellikleri ve anatomik varyasyonları bulunmaktadır. Glenoid yapısı ve akromiyon tipi varyasyon gösteren yapılarındandır. Bu çalışmada skapulanın morfometrik özellikleri ile birlikte anatomik varyasyonlarının değişkenliği değerlendirilmiş, literatürde yapılan çalışmalar ile karşılaştırılıp sonuçları ortaya konmaya çalışılmıştır. Pamukkale Üniversitesi Tıp Fakültesi Anatomi Anabilim Dalı'nda mevcut olan 16 sağ ve 24 sol olmak üzere toplam 40 adet skapula, milimetrik hassasiyet gösteren dijital kumpas ile ölçülmüştür. Bunun yanında tüm skapulaların akromiyon ve glenoid yapıları değerlendirilip tiplendirilmesi yapılmıştır. Kırk skapulanın ortalama yüksekliği $14,7 \mathrm{~mm}$, genişlik ortalaması 10,5 mm olarak bulunmuştur. Spina scapulae'nin uzunluk ortalaması 13,3 mm ölçülmüştür. Ortalama akromiyon uzunluğu ve genişliği sırasıyla 4,7 $\mathrm{mm}$ ve $2,3 \mathrm{~mm}$ olarak saptanmıştır. Akromiyon tiplendirilmesinde 10 akromiyonun düz, 15'inin konkav, 15 'inin ise çengelli olduğu görülmüștür. Akromiyonlar şekillerine göre ayrıldığında 14’ü kobra şekilli, 13’ü ara, 13'ü de kare şekilli olduğu izlenmiştir. Glenoidlerin 18'i virgül şekilli, 13’ü oval, 9'u ise armut şekilli olarak bulunmuştur. Anatomi laboratuvarında bulunan kırk skapulanın uzunluk parametrelerini ve tiplerini ortaya koymaya çalıştığımız bu çalışmada ulaşılan sonuçları literatürdeki diğer araştırmalarla karşılaştırdığımızda biyolojik çeşitlilikler görülmüştür. Bu tip antropometrik çalışmaların daha geniş serilerde, çok merkezli ve karşılaştırmalı olarak yapılmasına ihtiyaç duyulmaktadır

Anahtar Sözcükler: Skapula, tiplendirme, anatomik varyasyon

\section{Giriş}

Skapula omuz kuşağını oluşturan kemik yapılarından birisiolupgöğüsduvarınınarkasındakonumlanmaktadır. Ters üçgen pozisyonunda konumlanan skapulanın medial kenar1 margo medialis, lateral kenarı margo lateralis olarak adlandırıllı. Üçgenin alt köşesi angulus inferior, üst medial köşesi angulus superior, üst lateral köşesi ise angulus lateralis olarak isimlendirilir. Lateralde omuz eklemini ve akromiyoklavikuler eklemi oluşturan

\section{Morphometric Evaluation and Anatomical Variations of Scapula Samples}

\section{Abstract}

The scapula, one of the largest flat bones of the skeletal system, is located bebind the chest wall. Scapula has unique morphometric features and anatomical variations. Glenoid structure and acromion type are the structures that show variations. In this study, the morphometric properties of the scapula and the variability of the anatomical variations were evaluated, and the results were compared with the studies in the literature. 40 scapulae, 16 right and 24 left, which are available at the Anatomy Department at Pamukeale University Faculty of Medicine, were measured with an electrocronic digital caliper with a millimeter precision. In addition, the acromion and glenoid structures of all scapulae were evaluated and typed. The mean beight of the 40 scapulae was $14.7 \mathrm{~mm}$ and the mean width was $10.5 \mathrm{~mm}$. The average length of spina scapulae was $13.3 \mathrm{~mm}$. The mean length and width of the acromion were $4.7 \mathrm{~mm}$ and $2.3 \mathrm{~mm}$, respectively. Acromion typing showed 10 straight, 15 concave and 15 notched acromia. When acromion was separated according to its shape, 14 were cobra shaped, 13 were intermediate and 13 were square shaped. 18 glenoid were comma-shaped, 13 were oval and 9 were pear-shaped. When we compared the results obtained in this study, which we tried to reveal the length parameters and types of the forty scapulae in the anatomy laboratory, biological diversities were observed. This type of anthropometric studies needs to be performed in larger series, multicentrally and comparatively.

Key Words: Scapula, typing, anatomical variation

skapula, medialde muskulotendinöz yapılar ile toraksa ve omurgaya omuz kuşağını ulaştırmaktadır. İskelet sisteminin kemiklerinin morfolojik ölçümleri arasında farklılıklar değişik coğrafyalar arasında olabileceği gibi Anadolu gibi zengin bir bölgede aynı coğrafik bölgede de farklılıklar görülebilmektedir (Güngör, 1998). İskelet sisteminin büyük yassı kemiklerinden birisi olan skapula kendine has farklı anatomik yapısı ve varyasyonları ile literatürde morfometrik çalışmaların 
konusu olmuştur.

Bu çalışmanın amacı Pamukkale Üniversitesi Tip Fakültesi Anatomi Anabilim Dalı'ndan temin edilen skapula örneklerinin morfometrik değişkenliklerini ve anatomik varyasyonlarını saptamak, literatürde yer alan çalışmalarla sonuçlarımızı karşılaştırmaktır.

\section{Gereç ve Yöntem}

Etik Kurul onayı alınmasının ardından Pamukkale Üniversitesi Tıp Fakültesi Anatomi Anabilim Dalı laboratuvarından elde edilen 16 sağ ve 24 sol olmak üzere toplamda 40 adet skapula milimetrik hassasiyet gösteren dijital kumpas ile ölçüldü. Ölçümler çalışmanın iki yazarı tarafindan tüm kemiklerin ayrı ayrı değerlendirmesi ile gerçekleştirildi. Sağ ve sol skapulaların maksimum yükseklik ve maksimum genişliği, spina scapulae uzunluğu, akromiyon uzunluğu ve genişliği, korakoakromiyal mesafe, akromiyon-gleonoid arası minimum uzaklık, glenoid boyu ve en uzun çapı değerlendirildi.

Bunun yanında akromiyon tipi Bigliani'nin tarif ettiği gibi düz, konkav ve çengelli olarak (Nyffeler ve Meyer, 2017), akromiyon şekli de kobra, kare ve ara form olarak gruplandırıldı (Boyan vd., 2018). Glenoid şekli virgül, armut ve ovoid olarak gruplandırıldı (Gupta vd., 2015).

\section{Bulgular}

Kırk skapulanın ortalama yüksekliği $14,7 \mathrm{~mm}$, ortalama genişliği 10,5 mm olarak bulundu. Spina scapulae uzunluk ortalamas1 13,3 mmidi. Akromiyonun ortalama uzunluğu $4,7 \mathrm{~mm}$, ortalama genişliği $2,3 \mathrm{~mm}$, korakoakromiyal en kisa mesafe uzunluk ortalamas $2,8 \mathrm{~mm}$, akromiyonglenoid arası en kısa mesafe uzunluk ortalaması 1,7 mm olarak ölçüldü. Akromiyonlar, Bigliani'nin yapmış olduğu tiplendirmeye göre değerlendirildiğinde (Saha ve Vasudeva, 2017); 10’u düz (\%25), 15'i konkav (\%37,5), 15 'i de $(\% 37,5)$ çengelli olarak izlendi. Akromiyonlar şekillerine göre değerlendirildiğinde ise 14'ünün (\%35) kobra şeklinde, 13’ünün $(\% 32,5)$ kare şeklinde, 13'ününde $(\% 32,5)$ ara formda olduğu görüldü. Glenoidin en geniş çap ortalaması $2,5 \mathrm{~mm}$ olarak bulunurken, ortalama glenoid uzunluğu 3,5 mm olarak ölçüldü. Glenoidler morfolojik olarak tiplendirildiğinde 18'i virgül şekilli (\%45), 13'ü oval (\%32,5), 9’u da armut şekilli $(\% 22,5)$ olduğu görüldü. Sağ ve sol skapulalara ait uzunluk parametrelerinin ortalamaları Tablo 1, Tablo 2 ve Tablo 3'de gösterilmiştir.

\section{Tartışma}

Çalışmamızda skapulaların ortalama yüksekliği 147 $\mathrm{mm}$, ortalama genişliği $105 \mathrm{~mm}$ olarak bulunmuştur. Kale ve arkadaşlarının çalışmasında ortalama skapula uzunluğu $186 \mathrm{~mm}$ olarak bizim çalışmamıza göre daha uzun bulunurken ortalama genişliği bizimle benzer
Tablo 1. Skapulaya ait uzunluk parametrelerinin ortalama değerleri

\begin{tabular}{cccc}
\hline & $\begin{array}{c}\text { Skapula } \\
\text { yüksekliği }\end{array}$ & $\begin{array}{c}\text { Skapular } \\
\text { genişlik }\end{array}$ & $\begin{array}{c}\text { Spina scapulae } \\
\text { uzunluğu }\end{array}$ \\
\hline Sol $(\mathrm{n}=24)$ & $14,8 \mathrm{~mm}$ & $10,6 \mathrm{~mm}$ & $13,3 \mathrm{~mm}$ \\
$\operatorname{Sağ~}(\mathrm{n}=16)$ & $14,5 \mathrm{~mm}$ & $10,4 \mathrm{~mm}$ & $13,2 \mathrm{~mm}$ \\
Tümü (n=40) & $14,7 \mathrm{~mm}$ & $10,5 \mathrm{~mm}$ & $13,3 \mathrm{~mm}$ \\
\hline
\end{tabular}

Tablo 2. Akromiyona ait uzunluk parametrelerinin ortalama değerleri

\begin{tabular}{ccccc}
\hline & $\begin{array}{c}\text { Akromiyon } \\
\text { uzunluğu }\end{array}$ & $\begin{array}{c}\text { Akromiyon } \\
\text { genişliği }\end{array}$ & $\begin{array}{c}\text { Korakoakromiyal } \\
\text { mesafe }\end{array}$ & $\begin{array}{c}\text { Akromiyon- } \\
\text { g 1 e n o i d } \\
\text { uzaklik }\end{array}$ \\
\hline $\begin{array}{c}\text { Sol } \\
(\mathrm{n}=24) \\
\mathrm{Sağ} \\
(\mathrm{n}=16)\end{array}$ & $4,8 \mathrm{~mm}$ & $2,4 \mathrm{~mm}$ & $2,7 \mathrm{~mm}$ & $1,7 \mathrm{~mm}$ \\
$\begin{array}{c}\text { Tümü } \\
(\mathrm{n}=40)\end{array}$ & $4,5 \mathrm{~mm}$ & $2,2 \mathrm{~mm}$ & $2,9 \mathrm{~mm}$ & $1,7 \mathrm{~mm}$ \\
\hline
\end{tabular}

Tablo 3. Glenoide ait uzunluk parametrelerinin ortalama değerleri

\begin{tabular}{ccc}
\hline & $\begin{array}{c}\text { Glenoid en geniş } \\
\text { çap }\end{array}$ & $\begin{array}{c}\text { Glenoid en uzun } \\
\text { boy }\end{array}$ \\
\hline Sol $(\mathrm{n}=24)$ & $2,5 \mathrm{~mm}$ & $3,5 \mathrm{~mm}$ \\
$\mathrm{Sağ}(\mathrm{n}=16)$ & $2,5 \mathrm{~mm}$ & $3,5 \mathrm{~mm}$ \\
Tümü $(\mathrm{n}=40)$ & $2,5 \mathrm{~mm}$ & $3,5 \mathrm{~mm}$ \\
\hline
\end{tabular}

olarak 107 mm olarak görülmüştür (Kale vd., 2004). Taşer ve Başaloğlu'nun (2003) çalışmasında ise ortalama yükseklik bizim sonuçlarımıza daha yakın şekilde $141 \mathrm{~mm}$ olarak bulunmuştur. Hindistan'da yapılan bir çalışmada ise ortalama skapula uzunluğu $135 \mathrm{~mm}$ olarak gösterilmiştir (Akhtar vd., 2016). Spina scapulae ortalama uzunluğu $133 \mathrm{~mm}$ olarak saptanmış olup, Taşer ve Başaloğlu'nun (2003) ortalama değeri 128 mm'ye benzer olduğu görülmüştür. Taşer ve Başaloğlu'nun çalışmasında 39 kadın skapula kemiği, 13 erkek skapula kemiği bulunmaktaydı. Kadın kemiklerinin erkeklere göre üç kat fazla olmasının ortalamayı aşağıya çektiğini düşünmekteyiz (Taşer ve Başaloğlu, 2003).

Çalışmamızda ortalama akromiyon uzunluğu 47 $\mathrm{mm}$, genişliği $23 \mathrm{~mm}$, korakoakromiyal mesafe 28 $\mathrm{mm}$, akromiyo-glenoid en kısa uzaklığ1 $17 \mathrm{~mm}$ olarak bulundu. Kuzey Hindistan'da yapılan araştırmada bu ortalama değerler sirasiyla $41 \mathrm{~mm}, 21 \mathrm{~mm}, 28 \mathrm{~mm}$ ve $26 \mathrm{~mm}$ olarak gösterilmiştir (Saha ve Vasudeva, 2017). Ülkemizde Taşer ve Başaloğlu'nun (2003) çalışmasında ise bu ortalama değerler sirasiyla $43 \mathrm{~mm}, 22 \mathrm{~mm}, 31$ $\mathrm{mm}$ ve $21 \mathrm{~mm}$ olarak bildirilmiştir. Sonuçlarımızın literatürdeki ortalamalar ile benzerlik gösterdiğini düşünmekteyiz.

Çalışmamızdaki akromiyonların 10'u düz (\%25), 15’i konkav $(\% 37,5), 15 ’$ i de $(\% 37,5)$ çengelli olarak 
görüldü, Coşkun ve arkadaşlarının (2006) çalışmasında $\% 11$ düz, $\% 73$ konkav, $\% 17$ çengelli olarak gösterilmiştir. Ülkemizde yapılan diğer bir çalışmada ise $\% 45,2$ düz, \%32,2 konkav, \%22,6 çengelli olarak bildirilmiştir (Kale vd., 2004). Çalışmamızdaki akromiyonların 14'ünü (\%35) kobra şeklinde, 13'ünü (\%32,5) kare şeklinde, 13 'ünü de $(\% 32,5)$ ara formda izledik. Coşkun ve arkadaşlarının çalışmasında ise akromiyonların \%31'i kobra şeklinde, \%13'ü kare şeklinde, \%56's1 ise ara form olarak bildirilmiştir (Coşkun vd., 2006). Boyan ve arkadaşlarının (2018) araştırmasında akromiyonların $\% 45,5$ 'i kobra, \%7,5'i kare, \%47'si ara form olarak tanımlanmıştır. Gerek Bigliani'nin yapmış olduğu tiplendirmede, gerekse de akromiyon şekline göre yapılan tiplendirmede araştırmacılar arasındaki farklılıkların yapılan değerlendirmelerin objektif parametrelerden yoksun olmasından kaynaklandığını düşünüyoruz.

Araştırmamızda glenoidin en geniş çapının ortalamasın $25 \mathrm{~mm}$ ve ortalama glenoid uzunluğunu $35 \mathrm{~mm}$ olarak saptadık. Akhtar ve arkadaşlarının (2016) çalışmasında en geniş glenoid çapı ortalaması $23 \mathrm{~mm}$, ortalama glenoid uzunluğu ise $35 \mathrm{~mm}$ olarak bildirilmiştir. Ülkemizde ise Taşer ve Başaloğlu'nun (2003) çalışmasında bu değerler sırasıyla $25 \mathrm{~mm}$ ve 34 mm olarak sunulmuştur. Kendi sonuçlarımızın literatürle benzerlik gösterdiğini düşünüyoruz. Çalışmamızda glenoidler morfolojik olarak tiplendirildiğinde 18 'i virgül şekilli (\%45), 13’ü oval (\%32,5), 9’u da armut şekilli $(\% 22,5)$ izlendi. Bu sonuçlar literatürle karşılaştırıldığında farklılık göstermektedir. Akhtar ve arkadaşlarının (2016) çalışmasında glenoidlerin yarısını armut şekilli olanlar oluşturmaktaydı. Yine Hindistanda yapılan diğer bir çalışmada da armut şekli en fazla görülen olarak bildirilmiştir (Rajput vd., 2012).

Skapulaya ait morfometrik ölçümlerimizi tanımladığımız bu çalışmanın bir sebep veya sonuç olmasından ziyade süreç içerisinde bir parça olduğunu düşünüyoruz. Skapulanın ortalama ölçüm değerlerini bilmek ortopedi ve travmatolojide skapulaya yönelik cerrahî girişimleri de etkileyebilecektir. Sözgelimi ortalama glenoid çapını bilmek glenoid kırı̆̆ı sırasında uygulanacak vida boyu hakkında da fikir sahibi olmayı beraberinde getircektir ya da ortalama skapula yüksekliği ve genişliği hakkında bilgi sahibi olmak kırık sırasında uygulanacak skapula plağının boyutu hakkında da bilgi sahibi olmayı gerektirecektir. Antropolojide skapula boyutlarına bakarak cinsiyet belirlenmesi ise bilimin bir başka koludur (Özer vd., 2006).

\section{Sonuç}

Bu çalışmada Pamukkale Üniveristesi Tıp Fakültesi Anatomi Anabilim Dalı laboratuvarından elde edilen 40 kuru skapula kemiği üzerinde ölçümler yaparak, morfometrik değişkenlikleri saptadık ve literatürle karşılaştırdık. Skapulaya ait ortalama uzunluk ölçüm değerlerini, akromiyon ve glenoid tiplendirmelerini diğer araştırmalarla karşılaştırdığımızda faklılıklar görülse de; bu tip antropometrik çalışmaların daha geniş serilerde, çok merkezli ve karşılaştırmalı olarak yapılmasına ihtiyaç duyulmaktadir.

\section{Kaynakça}

Akhtar, M., Kumar, B., Fatima, N., ve Kumar, V. (2016). Morphometric analysis of glenoid cavity of dry scapulae and its role in shoulder prosthesis. International Journal of Research in Medical Sciences, 4(7), 2770-2776. https://doi. org/10.18203/2320-6012.ijrms20161948

Boyan, N., Ozsahin, E., Kizilkanat, E., Soames, R. W., ve Oguz, O. (2018). Assessment of scapular morphometry. International Journal of Morphology, 36(4), 1305-1309. https://doi. org/10.4067/S0717-95022018000401305

Coskun, N., Karaali, K., Cevikol, C., Demirel, B. M., ve Sindel, M. (2006). Anatomical basics and variations of the scapula in Turkish adults. Saudi Medical Journal, 27(9), 1320-1325.

Gupta, S., Magotra, R., ve Kour, M. (2015). Morphometric analysis of glenoid fossa of scapula. Journal of Evolution of Medical and Dental Sciences, 4(45), 7761-7766. https://doi.org/10.14260/ jemds/2015/1129

Güngör, A. (1998). Neolitik Dönemde beslenmenin insan morfolojisine yansimaları. Ankara Üniversitesi DTCF Dergisi, $\quad 38(1-2), \quad 368-370 . \quad$ https://doi.org/10.1501/ Dtcfder 0000001264

Kale, A., Edizer, M., Aydın, E., Demir, M. T., Dokuz, C., Çorumlu, U. (2004). Scapula morfometrisinin incelenmesi. Dirim, Kasım-Aralık, 26-35.

Nyffeler, R. W., ve Meyer, D. C. (2017). Acromion and glenoid shape: Why are they important predictive factors for the future of our shoulders? EFORT Open Reviews, 2(5), 141-150. https://doi.org/10.1302/2058-5241.2.160076

Özer, İ., Katayama, K., Sağir M., Güleç E. (2006). Sex determination using the scapula in medieval skeletons from East Anatolia. Collegium antropologicum, 30(2), 415-419.

Rajput, H. B., Vyas, K. K., ve Shroff, B. D. (2012). A study of morphological patterns of glenoid cavity of scapula. National Journal of Medical Research, 2(4), 504-507.

Saha, S., ve Vasudeva, N. (2017). Morphometric evaluation of adult acromion process in North Indian population. Journal of Clinical and Diagnostic Research, 11(1), AC08-AC11. https://doi. org/10.7860/JCDR/2017/21060.9312

Taşer, A. F., ve Başaloğlu, H. (2003). Skapulanın morfometrik ölçümleri. Ege Thp Dergisi, 42(2), 73-80



Bu makale Creative Commons Attf-GayriTicari 4.0 Uluslararası (CC BY-NC 4.0) lisansının hüküm ve şartları altında yayımlanan açık erişimli bir makaledir. 